\title{
How Do Different Faces of Paternalistic Leaders Facilitate or Impair Task and Innovative Performance? Opening the Black Box
}

Journal of Leadership \&

Organizational Studies

2020, Vol. 27(2) 138-152

(C) The Authors 2019

Article reuse guidelines:

sagepub.com/journals-permissions

DOI: $10.1177 / 1548051819833380$

journals.sagepub.com/home/jlo

(S)AGE

\author{
Zahide Karakitapoğlu-Aygün', Lale Gumusluoglu', and Terri A. Scandura²
}

\begin{abstract}
There is a growing amount of research integrating leadership and positive organizational behavior literatures in order to understand the processes through which leadership contributes to performance. One such mechanism through which leaders influence performance is psychological capital (PsyCap). Particularly, paternalistic leadership, which is a leadership style that combines discipline, authority, and power with fatherly benevolence, may be a critical antecedent to the development of followers' PsyCap. Yet no studies to date have investigated how paternalistic leaders affect followers' PsyCap, which, in turn, influences their task and innovative performance. To this end, based on a sample of 409 Turkish employees and their 72 leaders, the current study investigates the effects of three dimensions of paternalistic leadership (i.e., benevolent, authoritarian, and authoritative) on followers' leader-rated task and innovative performance. While there were no significant mediation effects for task performance, the results revealed that both benevolent and authoritative leadership positively influenced innovative performance through enhancing followers' PsyCap. Authoritarian leadership, however, has negative effects on PsyCap, which, in turn, mediates the effect on innovative performance of followers. The theoretical and practical implications of our findings, along with suggestions for future research, are discussed.
\end{abstract}

\section{Keywords}

paternalistic leadership, benevolent leadership, authoritarian leadership, authoritative leadership, psychological capital, task performance, innovative performance

Leaders play a key role in the creation and maintenance of processes that enhance follower performance (Gong, Huang \& Farh, 2009; Gooty, Gavin, Johnson, Frazier, \& Snow, 2009; Gupta \& Singh, 2015; Paulsen, Maldonado, Callan, $\&$ Ayoko, 2009). One such process that transfers the effects of leadership to follower outcomes is psychological capital (PsyCap). PsyCap refers to an individual's positive psychological state of development, which includes self-efficacy, optimism, hope, and resilience (Luthans \& Youssef, 2007; Luthans, Youssef, \& Avolio, 2007). Recent research has shown that PsyCap is an important antecedent of not only high task performance but also creative and innovative performance at the workplace (Huang \& Luthans, 2015). Indeed, prior research indicated that PsyCap is a state-like construct that can be developed by leaders (Luthans \& Avolio, 2003; Newman, Ucbasaran, Zhu, \& Hirst, 2014; Woolley, Caza, \& Levy, 2010). Although there has been an increasing amount of research integrating leadership and PsyCap literatures, there is a need to open this black box especially in Eastern countries characterized by collectivism and high power distance, where expected leader behaviors are quite different than those in individualistic Western contexts. One of the most prevalent and effective leadership styles in these Eastern contexts is paternalistic leadership (PL) (Aycan, Schyns, Sun, Felfe, \& Saher, 2013; Pellegrini \& Scandura, 2008). Although this leadership style is highly relevant for fostering the psychological resources of employees because of its person-centered approach, there is scant research examining its effects on PsyCap. To this end, the present study integrates $P L$ and PsyCap literatures and proposes that dimensions of PL (i.e., benevolent, authoritarian, and authoritative leadership) serve as critical antecedents to the development of followers' PsyCap, which, in turn, influence followers' task and innovative performance.

\footnotetext{
'Bilkent University, Ankara, Turkey

${ }^{2}$ University of Miami, Miami, FL, USA

Corresponding Author:

Zahide Karakitapoğlu-Aygün, Bilkent University, Faculty of Business Administration, 06800 Bilkent, Ankara, Turkey.

Email: zkaygun@bilkent.edu.tr
} 
PL suggests that people in authority consider it an obligation to provide protection to those under their care and, in exchange, expect loyalty and deference (Aycan, 2001, 2006; Farh \& Cheng, 2000). The traditional business context in Turkey is relatively collectivistic and high in power distance (Aycan, Kanungo, Mendonce, Kaicheng, \& Deller, 2000). In agreement with these cultural values, PL is a prevalent management style in the Turkish context (Berkman \& Özen, 2007; Erben \& Güneşer, 2008) where employees tend to form and maintain close relationships with their leaders as well as avoid conflict with them. Leaders provide support and protection to their employees, act like father/ mother figures, and show concern for their followers' personal and family-related problems. Such leaders get to know each employee and participate in their special days (birthdays, weddings, funerals, etc.). Even in R\&D contexts, Turkish leaders are expected to act like parental figures, and R\&D workers want to maintain harmonious relationships with these leaders (Karakitapoğlu-Aygün \& Gumusluoglu, 2013a, 2013b; Gumusluoglu, KarakitapoğluAygün, \& Scandura, 2017).

Based on these observations, in the current study we, first, test how different dimensions of PL are associated with followers' PsyCap. More specifically, by integrating PL and positive organizational behavior literatures, we propose that benevolent and authoritative leadership will have positive influences on followers' psychological strength, while authoritarian leadership will have negative effects. Second, we contribute to leadership, PsyCap, and innovation literatures by examining the mediating role of PsyCap in understanding how PL facilitates or impairs not only task performance but also innovative performance, which is extremely important for organizations to survive in today's rapidly changing world.

\section{Literature Review and Hypotheses}

\section{Paternalistic Leadership}

PL is defined as a leadership style that combines discipline, authority, and power with fatherly benevolence including different dimensions (Aycan, 2006; Cheng, Chou, Wu, Huang, \& Farh, 2004; Farh \& Cheng, 2000). Benevolence subdimension of PL refers to leader behaviors that demonstrate individualized, holistic concern for subordinates' personal and familial well-being. Authoritarianism dimension refers to leader behaviors that assert authority and control and demand unquestioning obedience from subordinates. Recently, in her refinement of paternalism construct, Aycan (2006) contrasted authoritarian leadership with authoritative leadership. She claims that the leader behavior shared by authoritarian and authoritative leadership is "control." What distinguishes the two styles is the underlying intent. In authoritarian leadership, a leader exploits rewards and punishments to make subordinates comply; in return, subordinates show conformity to receive rewards or avoid punishment. In other words, the underlying intent of authoritarian leadership is "people-control." Authoritative leaders also exercise control, but the underlying intent is to help employees reach organizational goals, as well as to promote subordinate welfare and development. Subordinates understand that the rules are for their benefit and respect the leader's decisions and willingly comply with them (Aycan, 2006). That is, the motive behind authoritative leadership is "task-control." Based on this reasoning, the current study employs a new conceptualization by Scandura (2017) that captures the authoritarian and authoritative dimensions separately in addition to the third traditional dimension of paternalism, namely, benevolence.

Previous studies reported positive effects of benevolence on task performance, while studies on authoritarianism referred to negative effects (Chan, Huang, Snape, \& Lam, 2013; Chan \& Mak, 2012; Wu, Huang, Li, \& Liu, 2011). Although the role of different leadership styles such as transformational leadership on creative and innovative performance is well established (Gumusluoglu \& Ilsev, 2009; Scott \& Bruce, 1994; Tierney, Farmer, \& Graen, 1999), the linkage between PL and innovative performance has not been much examined. Among a few of those studies, Wang and Cheng (2010) found a strong positive relationship between benevolence and creativity at the individual level when either creative role identity or job autonomy is high. In another study, Gumusluoglu et al. (2017) found that benevolent leaders facilitate both within-and cross-team innovative behaviors in $R \& D$ contexts through creating strong identifications with the team and the R\&D department, respectively. Moreover, in a recent study examining authoritarianism, Guoa et al. (2018) showed that employees under authoritarian leaders choose to remain silent and exhibit lower levels of creative behavior. These studies support the link between PL and innovation, yet there is a need to understand the underlying processes that explain how authoritarian, authoritative, and benevolent leaders influence task and innovative performance of their followers.

Indeed, some past research studied different mediating mechanisms in the PL-task performance relationship. For example, in one such study, Chan et al. (2013) showed that PL shaped the construction of subordinate's organizationbased self-esteem and evaluations which, in turn, influenced their performance. Similarly, Chan and Mak (2012) illustrated that leader-member exchange partially mediated the relationship between benevolence and follower task performance. Besides, Chen, Eberly, Chiang, Farh, and Cheng (2014) reported that affective trust mediated the relationship between benevolent PL and employee performance. In another study, $\mathrm{Wu}$ et al. (2011) found that benevolent leadership positively influenced interactional justice perceptions and trust-in-supervisor, which, in turn, 
facilitated work performance, while authoritarian leadership had a negative impact on trust-in-supervisor, which impaired work performance. All in all, although previous research looked at some relational and psychological processes, there is a paucity of research studying positive psychological resources as a mechanism through which these paternalistic leaders influence performance. This is surprising given that PL involves a particularly person-centered approach (Chou, Sibley, Liu, Lin, \& Cheng, 2015), and thus, it may have strong influences on followers' PsyCap. For example, since benevolent leaders are interested not only in their followers' professional but also in their personal lives, subordinates under such leaders may have a more positive outlook about their future personal and work life (optimism) and have the ability to overcome obstacles (resilience). Similarly, authoritative leaders' orientation toward follower development in task-related issues may enhance followers' hope and confidence in themselves to accomplish these tasks. On the other hand, authoritarian leaders may impede their employee's psychological states by creating pressure, anxiety, fear, and uncertainty. To this end, we investigate how different dimensions of paternalism facilitate or damage followers' positive psychological states, which, in turn, influence their performance.

\section{Psychological Capital}

PsyCap is a multidimensional construct including hope, optimism, efficacy, and resilience (Luthans \& Youssef, 2007; Luthans, Youssef, \& Avolio, 2007). It consists of attitudinal and cognitive resources that have a positive impact on performance. Self-efficacy refers to the positive belief or confidence in one's ability to successfully complete a task. Employees high in self-efficacy perceive that they have the ability to take action to change their environment, expend high levels of effort, and are persistent in the effort they put until the task is accomplished. Optimism is a positive evaluation of one's future including both social and material aspects of the life. Optimists distance themselves from negative life events; thus, they are less likely to give up and more likely to have a more positive outlook about their future. Hope is composed of two dimensions: willpower and pathways (Snyder \& Lopez, 2002). Willpower refers to the ability to set valued goals, and pathways refer to the psychological resources to find multiple and alternative paths to accomplish the goal. Finally, resilience represents the ability to withstand and bounce back from failures, setbacks, and stressful situations. Resilient people are more likely to recover from negative emotional difficulties and are more prone to experience positive emotions in stressful times. Although it has been described as a multidimensional construct, PsyCap has been shown to account for more variance in predicting outcomes when considered as a core construct as compared with individual dimensions (Luthans,
Youssef-Morgan, \& Avolio, 2015; Luthans, Avolio, Avey, \& Norman, 2007). Pointing to the shared mechanisms between them, Luthans and Youssef-Morgan (2017) claim that these psychological resources "may travel together and interact synergistically to produce differentiated manifestations over time and across contexts" (p. 343). In light of these previous studies (Clapp-Smith, Vogelgesang, \& Avey, 2009; Luthans et al., 2005; Luthans, Avolio, et al., 2007), we are primarily concerned with the combined effect of selfefficacy, hope, optimism, and resilience on performance and treated PsyCap as a unitary construct while assessing its mediation effects between dimensions of PL and performance in the current study.

Recently, Luthans and Youssef-Morgan (2017) mentioned about key theoretical mechanisms through which PsyCap operates, namely, conation, positive cognitive appraisals, positive emotions, and social mechanisms. First of all, conation refers to agentic, planful, and goal-oriented behaviors including free will and freedom to make choices, which promote a positive reaction when obstacles are encountered. Second, positive cognitive appraisals help mental reframing and interpreting neutral or negative events in a more positive light. Such positive appraisals reduce negativity biases and enhance perseverance, rather than giving up when faced with obstacles. Thirdly, PsyCap triggers positive emotions that can facilitate widening one's cognitive repertoires leading to more innovative and creative behavior (Luthans, Youssef, \& Rawski, 2011). Finally, social support and help from others are important for building efficacy and resilience. Improved relationships and strong networks can facilitate optimism and hope, as well.

Since PsyCap represents employees' psychological resources that are rooted in positive beliefs, emotions and cognitions, and social support, people who have higher levels of PsyCap are more confident and energized to achieve goals and put forth effort that is reflected in higher performance over long periods of time. This is because they will have willpower and the energy to succeed at a given task (hope), use their cognitive resources and show necessary effort and actions to achieve their goals (self-efficacy), have positive expectations about the results (optimism), and overcome difficulties and bounce back from adversity or failure and repeat attempts to be successful at those times (resilience). Supporting these points, many studies reported positive associations between PsyCap and self- or leader-rated performance as well as objective performance scores obtained from human resources department (Avey, Luthans, \& Youssef, 2010; Gooty et al., 2009; Luthans, Avolio, et al., 2007; Luthans, Norman, Avolio, \& Avey, 2008; Peterson, Luthans, Avolio, Walumbwa, \& Zhang, 2011). This positive association was even established in longitudinal studies, which found that employees who demonstrated an increase (or decrease) in PsyCap also showed an increase (or decrease) in their leader-rated performance (Peterson et al., 2011). 
Having necessary positive psychological resources is not only important for task performance but also critical for creative and innovative performance at the workplace. Innovative performance refers to the intentional introduction and application of new ideas, products, processes, and procedures to work roles, units, or organizations (West \& Farr, 1989) and is vital to survive in dynamic, fast-paced global environmental contexts in today's world. Yet there is a scarcity of research studying the linkage between PsyCap and creative and innovative performance in the literature. One notable exception is a study by Huang and Luthans (2015), which found a strong positive relationship between PsyCap and creativity. Accordingly, individuals high in PsyCap are more likely to be positive toward uncertainties, search for alternative solutions to problems, take a broader perspective in their tasks, and continuously explore opportunities and new ideas. As indicated by Huang and Luthans (2015), "The core construct of PsyCap is a rich psychological mechanism which individuals might rely on to generate creative outcomes" (p. 466). In another study, Luthans et al. (2011) found that core construct of PsyCap and reinforcing feedback were positively related to problem solving and innovative performance, especially when mediated through a mastery-oriented mind-set. In a similar vein, Rego, Sousa, Marques, and Cunha (2012) illustrated that when employees are psychologically stronger, they have higher levels of intrinsic motivation, and therefore are more inclined to search for and propose creative ideas. In light of these observations, one of our aims in the present study is to delineate the role of PsyCap on not only task performance but also innovative performance. While doing that, we study how different dimensions of PL enhance or hinder task and innovative performance through their effects on subordinates' psychological resources. Below, these linkages between dimensions of PL, PsyCap, and performance are discussed.

\section{Benevolent Leadership and Performance: The Mediating Role of PsyCap}

Benevolent leadership can influence follower performance especially through the "positive emotions" and "social support" mechanisms of PsyCap (Luthans \& Youssef-Morgan, 2017). First of all, when benevolent leaders show caring and nurturing behaviors, they are likely to induce positive feelings among their followers who experience high levels of trust, emotional bonding, warm feelings, comfort, and identification with the leader to continue the positive cycle (Farh \& Cheng, 2000; Wasti, Tan, \& Erdil, 2010). All these positive feelings bring about personal bonding and sharing of positive affect between the two people (Webber, 2002). These affective elements flourish further as individuals engage in acts of social reciprocity. Second, benevolent leaders who act like parental figures provide support to their followers' both personal and professional lives. In other words, such leaders help their followers cope with problems and obstacles by building and maintaining healthy interpersonal relationships and providing social support (Rego et al., 2012). Consistent with this parental style, these leaders try to get to know each employee, are interested in all aspects of their lives (e.g., attending their wedding ceremonies, funerals, special days, etc.), and help them especially in difficult times. For example, the general manager of a Turkish company accompanied a worker's child who was receiving cancer treatment in England because the family did not speak English (Paşa, Kabasakal, \& Bodur, 2001). It is also not surprising that benevolent leaders in Turkey pay the tuition fees for their employees' children who are in need. This emotional and social support from one's leader can strengthen follower's efficacy (Bandura, 1997) and also, especially in adverse times, instill positive psychological states into followers such as more positive outlook about one's future (hope) and higher levels of ability to recover from negative work and life events (resilience). Reliance on one's leader especially when the resources are scarce or lacking can also enhance optimism and "every cloud has a silver lining" thinking.

Taken together, these arguments imply that positive emotions and perceived support created by benevolent leaders make followers more willing to sustain their willpower, achieve challenging goals, approach problems from different perspectives, and contribute to the success of their units by exhibiting higher levels of task and innovative performance. For example, Rego et al. (2012) reported that when leaders strengthen followers' positive psychological resources, these subordinates are more likely to take advantage of opportunities and challenges, choose challenging and difficult tasks, look for alternative and creative ways to overcome obstacles, and take more risks. These types of positive people tend to view problems from a broader perspective and be intrinsically motivated where they attribute success to their internal characteristics while distancing themselves from failures. They are more likely to exhibit creative behavior since they demonstrate a cognitive style favorable to taking new perspectives on problems and a working style conducive to persistent and energetic pursuit of one's work (Amabile, 1998). Thus, we hypothesize,

Hypothesis 1: PsyCap will mediate the positive relationship between benevolent leadership and (a) task performance and (b) innovative performance.

\section{Authoritarian Leadership and Performance: The Mediating Role of PsyCap}

Authoritarian leaders are claimed to exert power and control over their followers, expect absolute conformity and obedience, and punish them when they do not follow their 
rules and instructions (Aycan, 2006; Chan et al., 2013; Farh $\&$ Cheng, 2000). Therefore, these leaders could influence follower performance negatively through all the key theoretical mechanisms of PsyCap (i.e., conative, affective, cognitive, and social) (Luthans \& Youssef-Morgan, 2017). First of all, Farh and colleagues (Farh, Cheng, Chou, \& Chu, 2006) suggest that people-control-oriented authoritarian leaders display personal dominance, request conformity from their followers, and cannot truly motivate them. This emphasis on obedience and control may reduce followers' agentic, proactive, and planful goal-oriented behaviors since the external pressure to conform and perform is made salient by these leaders. Thus, followers' motivation and effort as well as mindfulness and sense of control will diminish under authoritarian leadership.

Second, these authoritarian leaders are likely to trigger negative emotions among their followers such as distrust, fear, anger, anxiety, and uncertainty (Guoa et al., 2018; Wu et al., 2011). Moreover, they cannot manage their emotions and are more likely to exhibit abusive behaviors at the workplace (Ertureten, Cemalcılar, \& Aycan, 2013). Thus, these leaders provoke destructive psychological processes and followers are more likely to feel helpless. The resulting negative affective states hinder rather than facilitate broadening one's thought-action repertoires and building and restoration of physical, social, and psychological processes (Luthans \& Youssef-Morgan, 2017), consequently resulting in poor performance.

Third, Chan et al. (2013) stated that authoritarian leaders view their followers as incompetent and dependent, and undermine their followers' abilities. In other words, these leaders signal their followers that they are not valuable, and they harm their followers' self-evaluations, self-esteem, and confidence in their capabilities. As a result, followers lacking positive self-worth and self-efficacy may not be passionate and motivated enough to show effort in performing tasks and achieving their goals. Such negative affectivity results in a pessimistic outlook (less optimism) where followers question their self-competence (low self-efficacy), cannot show positive adaptation patterns to overcome obstacles (low resilience), and attribute their failures to internal and stable characteristics while attributing success to external factors (less hope). These negative perceptions further increase subordinates' feelings of powerlessness resulting in less optimistic views of themselves, their leaders, jobs, and the organization in which they work.

Finally, unlike benevolent leaders, authoritarian leaders strive to maintain a distance with their followers and cannot maintain high-quality relationships with them. The distant nature of the relationship signals a strong disregard for the interests and perspective of their followers. Therefore, subordinates are likely to perceive these authoritarian behaviors as signs of disrespect and devaluation. These leaders are also likely to exert control by promising rewards for compliance and threatening punishment for disobedience. Consequently, followers of such authoritarian leaders feel that they cannot trust the leader since she or he will not support them when needed, impairing the quality of the relationship with the leader and the amount/level of perceived social support from the leader.

In line with the above-mentioned theoretical mechanisms, we propose that authoritarian leadership influences task and innovative performance through its negative influences on the psychological resources of the followers by impeding the motivational and emotional forces of confidence, self-worth, optimism, and hope. Such lower levels of PsyCap triggered by authoritarian leaders may paralyze followers such that they are not willing to go beyond their job responsibilities for fear of doing something wrong and then being reprimanded. This hence motivates them to withhold their efforts in performing the tasks. Similarly, under such fear-inspiring leaders, followers feel less psychological strength resulting in reluctance to generate and exchange novel ideas and solutions to the problems (Guoa et al., 2018; Zhang, Huai, \& Xie, 2014). Thus, we hypothesize,

Hypothesis 2: PsyCap will mediate the negative relationship between authoritarian leadership and (a) task performance and (b) innovative performance.

\section{Authoritative Leadership and Performance: The Mediating Role of PsyCap}

Authoritative leaders clearly define and communicate goals, strategy, and performance standards in accomplishing tasks. They are skillful in building individual initiative on the part of followers. As mentioned before, authoritative leaders are different from authoritarian leaders in that they exercise control and set the boundaries in order to help employees reach their goals, as well as promoting their welfare and development (Aycan, 2006). They emphasize the reasons for work-related rules, set clear expectations about the tasks and performance targets, and provide feedback. Consequently, subordinates know the rules of the game and willingly comply with these rules. They don't experience confusion or ambiguity about what is expected from them since the leader clearly explains his or her expectations in advance. Kim and Mauborgne (1997) argued that such explanation and expectation clarity provided by these leaders creates a fair process in the company and enhances subordinate motivation. When the leader communicates expectations clearly, employees know up front by what standards they will be judged and the penalties for failure. Explanation of the rules and decisions makes people confident that the leader serves the overall interests of the company and allows employees to trust his or her intentions. 
Authoritative leadership can influence follower performance particularly through "agentic conation" and "cognitive appraisal" mechanisms of PsyCap (Luthans \& Youssef-Morgan, 2017). When authoritative leaders help subordinates understand the details of the work to reach their targets, this encourages followers to show planful, intentional, and self-controlled behaviors, which enhance job performance. This agentic and proactive control of motivation and effort will facilitate goal-directed energy whereby followers work hard to attain their goals. Furthermore, authoritative leaders are able to clear up subordinates' paths to goal accomplishment by clarifying their performance goals, the means through which they can effectively carry out tasks, and the standards by which subordinates' performance will be judged (House, 1996). When leaders emphasize goal achievement and set challenging goals, followers tend to have personal interest in the tasks they perform, which may evoke feelings of pleasure and intrinsic motivation. Intrinsic motivation affects innovative performance by influencing the likelihood that more innovative possibilities will be explored during task engagement (Amabile, 1988). Then, followers are likely to cope effectively with such difficulties by putting substantial effort into the job of innovation in order to identify and apply the strategies needed to succeed. Therefore, this task and goal orientation of the leader and the feedback provided by the leader to facilitate goal accomplishment can lead to positive cognitive appraisals where the follower may reframe and reinterpret situations more positively (optimism), have enhanced level of self-efficacy, as well as the motivation to pursue challenging goals (hope). Such positive cognitive appraisals can also result in heightened levels of perseverance (resilience).

All in all, path-goal clarifying behaviors of authoritative leaders minimize role ambiguity and confusion. High levels of role ambiguity are stressful and unpleasant for followers (Kahn, Wolfe, Quinn, Snoek, \& Rosenthal, 1964), which will likely reduce their PsyCap. Therefore, authoritative leaders can enhance followers' feelings of hope, optimism, and confidence by providing directions to pursue their goals, and a safe and fair environment to perform. Such an environment may allow for high levels of task performance as well as enhanced initiative and creativity. Therefore, we hypothesize,

Hypothesis 3: PsyCap will mediate the positive relationship between authoritative leadership and (a) task performance and (b) innovative performance.

\section{Method}

\section{Sample}

Data were collected from a heterogeneous sample of private and public organizations in Ankara, Turkey (total 24 organizations). Public organizations mostly included municipalities and ministries of health, education, and culture and tourism, while private firms included banks, construction firms, and private hospitals. The overall response rate was $74.36 \%$. The sample consisted of 409 white-collar professionals and their 72 leaders. The minimum number of employees from each organization was 3 , and the maximum was 41 , with an average of 17 . Of the participants, $60 \%$ were male, $38 \%$ were female, and $2 \%$ unidentified. Around $72 \%$ of the employees were from public organizations, and $28 \%$ were from private organizations. The average age of the leaders and employees was 46 years $(S D=7.17)$ and 35 years $(S D=8.72)$, respectively. The average tenure with the leader and the company were $4.25(S D=4.77)$ and 7.06 years $(S D=7.85)$, respectively.

\section{Procedure and Measures}

We first contacted managers and/or HR supervisors to obtain their permission for the study. They provided us with the names of the employees and their immediate leaders who agreed to participate. Data were collected by two separate questionnaires: one for the employees and the other for their immediate supervisors. The Turkish version of the scales was checked through back translations of the original translations (Brislin, 1970). Native speakers of English and Turkish also checked the scales for wording, accuracy, and clarity of items. On each survey, we used codes for employees and their leaders, and the surveys were matched. The surveys were distributed in envelopes to assure confidentiality, and respondents completed the surveys in their offices.

Paternalistic Leadership. Scandura's (2017) measure of PL was used that includes benevolent, authoritative, and authoritarian leadership dimensions. Six items were used for each dimension. Sample items for benevolence dimension are, "He/She is like an elder family member (father/ mother, elder brother/sister) to me," and "Beyond work relations, he/she expresses concern about my daily life." Sample items for authoritative leadership are, "He/She emphasizes the reasons for work-related rules," and "He/ She explains the consequences for my poor performance." Sample items for authoritarian leadership are "He/She asks me to obey his/her instructions completely," and "He/She punishes me when I can't accomplish my tasks." Employees evaluated the behaviors of their immediate leaders on a 5-point response scale ranging from 1 (strongly disagree) to 5 (strongly agree). We conducted a confirmatory factor analysis using LISREL (Jöreskog \& Sörbom, 1993) to test the three-dimension structure of PL. The three-factor model yielded an acceptable fit, $\chi^{2}(132)=1040.24, p<.01$; CFI (confirmatory fit index) $=.92$; NNFI (nonnormed fit index) $=.91 ; \mathrm{SRMR}$ (standardized root mean square residual) $=$ .09. All the factor loadings for each scale indicator and all the error variances were significant at $p<.05$. Furthermore, 
PL in the present study is treated as an individual-level variable as leaders may not behave in a uniform manner across followers and situations. Prior studies suggested that individual attitudes and behaviors are more likely to be affected by the leadership each individual receives from the leader as opposed to the average level of leadership received by the group (Gooty et al., 2009).

Psychological Capital. PsyCap was measured by a 24-item scale developed by Luthans, Avolio, et al. (2007) and Luthans, Youssef, et al., (2007) via subordinate surveys. Six items were used for each subscale of hope, resilience, optimism, and efficacy. Sample items are, "I feel confident helping to set targets/goals in my work area" (efficacy), "I can think of many ways to reach my current work goals" (hope), "I usually manage difficulties one way or another at work" (resilience), and "I always look on the bright side of things regarding my job" (optimism). Participants responded on a 6-point response scale ranging from 1 (strongly disagree) to 6 (strongly agree). As mentioned before, we treated PsyCap as an individual-level core construct and combined self-efficacy, hope, optimism, and resilience dimensions while computing the scale.

Task Performance. Performance was measured by three items from Wang and Takeuchi (2007) and Podsakoff and Mackenzie (1989). Immediate leaders evaluated the task performance of each of their employees on a 5-point response scale ranging from 1 (strongly disagree) to 5 (strongly agree). Sample items are, "He/she always completes the duties assigned to him/her," and "He/she fulfills all responsibilities required."

Innovative Performance. Innovative performance of the employees was measured by seven items from Janssen (2000). Immediate leaders were asked to rate their employees' innovative performance in the past year. Sample items are, "S/He created new ideas for difficult issues" (idea generation), "S/He mobilized support for innovative ideas" (idea promotion), and " $\mathrm{S} / \mathrm{He}$ transformed innovative ideas into useful applications" (idea realization). Leaders responded on a 5-point response scale ranging from 1 (not at all) to 5 (very).

Control Variables. Past research has identified several variables, such as age, gender, and tenure with the leader, as potential influences on how employees respond to leadership behavior and exhibit innovative behavior (Mumford, Scott, Gaddis, \& Strange, 2002). These demographic variables are also suggested to influence PsyCap (Luthans \& Youssef-Morgan, 2017). Hence, age, gender, and tenure with the leader are used as control variables. In addition, sector (public vs. private) at which the participants are working is also treated as a control variable since the extent to which innovative behavior is relevant and expected may be different in these public and private sectors (Bysted \& Hansen, 2013).

\section{Results}

Means, standard deviations, reliability estimates (Cronbach's alpha), and correlations among the study variables are shown in Table 1. We checked the correlations between control variables and the main study variables. Since none of them showed significant correlations, they were not included in subsequent analyses. Then, to examine construct distinctiveness of our measures, we performed confirmatory factor analysis using LISREL to test competing models. Preliminary analyses revealed that three reversed-coded PsyCap items (one from resilience and two from optimism dimensions) as well as one positively worded resilience item (i.e., "I usually take stressful things at work in stride") had very low factor loadings, and they were not statistically significant. Therefore, we deleted these four items. ${ }^{1}$ We first tested a single factor model combining PL, PsyCap, task, and innovative performance items. This model exhibited poor fit as anticipated, $\chi^{2}(1077)=$ 29021.11, $p<.01$; CFI $=.67$; NNFI $=.65$; SRMR $=.24$. Then, we tested a four-factor model where we combined all leadership items into the first factor, PsyCap, and task and innovative performance items into the second, third, and fourth factors, respectively. This four-factor model again yielded a poor fit, $\chi^{2}(1071)=9117.98, p<.01 ; \mathrm{CFI}=.83$; $\mathrm{NNFI}=.82 ; \mathrm{SRMR}=.10$. Finally, we considered PL items under three dimensions and tested a six-factor model. This model yielded the best fit, $\chi^{2}(1062)=5874.12, p<.01$; $\mathrm{CFI}=.88 ; \mathrm{NNFI}=.87$; SRMR $=.08$. Overall, we concluded that our measures were appropriate.

Leaders rated task and innovative performance of their employees, which introduces the possibility of nonindependence due to common raters. To assess this possibility, we calculated the intraclass correlation (ICC)(1) values for our main study variables (Bliese, 2000). The ICC(1) shows the amount of variance in a given variable that can be attributed to group membership. Since the number of organizations is relatively small in the current study (24) to yield valid results, we computed the ICC(1) scores for the 72 leaders. We found that the ICC(1) values were $.07, .06$, and .11 for authoritative, authoritarian, and benevolence dimensions of PL, respectively, and .04 for PsyCap. These results suggest that means are not strongly affected by group membership and there is considerable individual-level variability in these constructs, supporting our above-mentioned arguments. However, ICC(1) values were above the threshold for both task and innovative performance (.36 and .42 for task and innovative performance, respectively) indicating that a significant portion of the variance in the ratings of employees' performance could be accounted for by 
Table I. Descriptive Statistics for the Main Study Variables.

\begin{tabular}{llccccccc}
\hline & $M$ & $S D$ & 1 & 2 & 3 & 4 & 5 & 6 \\
\hline I. & Benevolent leadership & 3.14 & 1.08 & $(.77)$ & & & & \\
2. Authoritative leadership & 3.87 & .81 & $.45^{* * *}$ & $(.79)$ & & & & \\
3. Authoritarian leadership & 2.59 & .74 & $-.32^{* * *}$ & $-.42^{* * * *}$ & $(.91)$ & & & \\
4. PsyCap & 4.71 & .58 & $.24^{* * *}$ & $.26^{* * *}$ & $-.22^{* * *}$ & $(.93)$ & & \\
5. Innovative performance (leader-rated) & 2.98 & .82 & $.21^{* * *}$ & $-.13^{* *}$ & -.03 & $.22^{* * *}$ & $(.94)$ & \\
6. Task performance (leader-rated) & 3.93 & .77 & $.24^{* * *}$ & -.04 & -.01 & $.22^{* * *}$ & $.55^{* * *}$ & $(.87)$ \\
\hline
\end{tabular}

Note. $N=409$; reliabilities are reported in parentheses.

$* * p<.01$. *** $p<.001$.

Table 2. Unstandardized Path Estimates for PsyCap, Task, and Innovative Performance.

\begin{tabular}{|c|c|c|c|c|c|c|}
\hline & \multicolumn{2}{|c|}{ PsyCap } & \multicolumn{2}{|c|}{$\begin{array}{c}\text { Task } \\
\text { performance }\end{array}$} & \multicolumn{2}{|c|}{$\begin{array}{c}\text { Innovative } \\
\text { performance }\end{array}$} \\
\hline & Est. & SE & Est. & SE & Est. & SE \\
\hline $\begin{array}{l}\text { Benevolent } \\
\text { leadership }\end{array}$ & $.07^{*}$ & .04 & & & & \\
\hline $\begin{array}{l}\text { Authoritative } \\
\text { leadership }\end{array}$ & $.12^{* *}$ & .05 & & & & \\
\hline $\begin{array}{l}\text { Authoritarian } \\
\text { leadership }\end{array}$ & $-.08 *$ & .03 & & & & \\
\hline PsyCap & & & $.11^{\dagger}$ & .07 & $.13 * * *$ & .04 \\
\hline
\end{tabular}

Note. $N=409$; Est. $=$ the unstandardized estimate; $S E=$ standard error. $t_{p}=.10 . *_{p}<.05 . * *_{p}<.01$. ${ }^{* * *} p<.001$.

differences in the leaders that provided the ratings. Therefore, our data required an analytical tool that account for the nested structure using multilevel modeling. Multilevel modeling can be used to control for potential dependencies and to account for the nested nature of data, even when all variables are at the individual level of analysis, as is the case in the present study. As such, we used multilevel path analysis in Mplus (Muthén \& Muthén, 1998-2017) to test our hypotheses where we controlled for the leader id cluster variable. We used grand-mean centering to facilitate the interpretation of the results and to reduce the potential problems with multicollinearity.

\section{Hypothesis Testing}

The results from our multilevel path analysis where all the predictors and the outcomes were put in the analysis altogether are presented in Tables 2 and 3. As can be followed from Table 2, benevolent and authoritative dimensions of PL predicted PsyCap positively, while authoritarian leadership predicted it negatively. Furthermore, PsyCap was found to be a significant predictor of innovative performance $(\gamma=.13, p=.001)$, but not for task performance $(\gamma=.11, p=.10)$, which still can be considered as "a trend" given the conservative statistical methods used in the study (controlling for nestedness as well as putting all the independent and dependent variables in the same analysis).

Our first hypothesis predicted that PsyCap would mediate the relationship between benevolent leadership and task (Hypothesis 1a), and innovative performance (Hypothesis 1b). The mediating effect of the PsyCap was not statistically significant for task performance (an indirect effect of .00 with a $95 \%$ CI ranging from -.005 to .019). Furthermore, although, the indirect effect was not statistically significant for innovative performance, it showed a trend at $p=.08$ (an indirect effect of .01 with a $90 \%$ CI ranging from .001 to .019). Therefore, Hypothesis 1a was not supported, but there was a trend for Hypothesis $1 b$.

Paralleling the previous result, the mediating effect of PsyCap in authoritarian leadership and performance link was not significant for task performance (an indirect effect of -.00 with a $95 \%$ CI ranging from -.023 to .005 ). However, the indirect effect for innovative performance was negative and marginally significant at $p=.06$ (an indirect effect of -.01 with a $90 \%$ CI ranging from -.020 to $-.001)$. Hence, these results suggest rejection of Hypothesis 2a, but they provide a support for Hypothesis $2 b$.

Finally, PsyCap did not mediate the relationship between authoritative leadership and task performance supporting the aforementioned authoritarian and benevolent leadership findings (an indirect effect of .01 with a 95\% CI ranging from -.005 to .030). But support was found for this mediating effect on innovative performance (an indirect effect of .02 with a $95 \% \mathrm{CI}$ ranging from .002 to .028]). Thus, Hypothesis 3a was not supported, but Hypothesis $3 \mathrm{~b}$ was supported.

\section{Supplementary Analyses}

As a supplemental analysis, we explored the possibility of direct effects of three dimensions of PL on task and innovative performance. None of the direct effects on task performance was significant $(\gamma=.00, p=.985, \gamma=.05$, $p=.431, \gamma=-.01, p=.621$ for authoritative, benevolent, and authoritarian leadership dimensions, respectively). Similarly, both authoritative and authoritarian leadership 
Table 3. Mediation Results.

\begin{tabular}{|c|c|c|c|c|}
\hline & \multirow{2}{*}{$\begin{array}{l}\text { Indirect } \\
\text { effect }\end{array}$} & \multirow[b]{2}{*}{ SE } & \multicolumn{2}{|c|}{ 95\% Confidence interval } \\
\hline & & & Lower bound & Upper bound \\
\hline Benevolent leadership $\rightarrow$ PsyCap $\rightarrow$ Task performance & .00 & .006 & -.005 & .019 \\
\hline Authoritative leadership $\rightarrow$ PsyCap $\rightarrow$ Task performance & .01 & .009 & -.005 & .030 \\
\hline Authoritarian leadership $\rightarrow$ PsyCap $\rightarrow$ Task performance & -.00 & .007 & -.023 & .005 \\
\hline Benevolent leadership $\rightarrow$ PsyCap $\rightarrow$ Innovative performance & $.0 \mathrm{I}^{\mathrm{a}}$ & .005 & $.001^{\mathrm{c}}$ & $.019^{c}$ \\
\hline Authoritative leadership $\rightarrow$ PsyCap $\rightarrow$ Innovative performance & $.02 *$ & .007 & .002 & .028 \\
\hline Authoritarian leadership $\rightarrow$ PsyCap $\rightarrow$ Innovative performance & $-.01^{b}$ & .006 & $-.020^{c}$ & $-.00 I^{c}$ \\
\hline
\end{tabular}

Note. $N=409$; Est. $=$ the unstandardized estimate; $S E=$ standard error. ${ }^{a} p=.08 .{ }^{b} p=.06 .{ }^{c} 90 \%$ confidence intervals are reported.

$p<.05$.

did not have direct effects on innovative performance $(\gamma=-.02, p=.650$ for authoritative and $\gamma=-.00, p=.952$ for authoritarian leadership). However, the direct effect of benevolent leadership on innovative performance was marginally significant $(\gamma=.09, p=.070)$.

\section{Discussion}

This study is among the first attempts to open the PL and performance black box and shows that PsyCap is an important explanatory mechanism in this relationship. In doing so, our contributions are twofold: First, by integrating leadership and positive organizational behavior literatures, we found that dimensions of PL serve as important antecedents of PsyCap. This is an important contribution to both PsyCap and leadership literatures, which have mostly focused on leadership theories developed in the West (i.e., transformational leadership, authentic leadership, etc.). Our findings illustrated that PL, as an Eastern leadership style, also has significant effects on followers' psychological strength. Second, we examined PsyCap as an antecedent of performance, especially innovative performance for which empirical studies remain scarce. Our study supports the findings of those few research that pointed to the positive effects of PsyCap on creative and innovative performance (Huang \& Luthans, 2015; Rego et al., 2012). While our results showed no mediation effects of PsyCap on the relationships between PL and task performance, it was a mediator between all three dimensions of PL and innovative performance. As expected, we found that authoritarian leadership is negatively related, but both benevolent and authoritative leadership are positively related to PsyCap, which, in turn, enhanced innovative performance. Furthermore, post hoc analyses revealed that among these three dimensions of PL, only the benevolent leadership style has direct effects on innovative performance.

Our analyses imply that there is only a marginal effect of PsyCap on task performance. This finding may be related to the nature of the task performance measure employed in the current study, as further discussed in the limitations section. Our operationalization of task performance is based on whether employees fulfilled their responsibilities in a very general sense, as compared with performance measures employed in previous studies that included more cognitive aspects of performance (e.g., quality of work, quality of customer service, complexity of assignment, teamwork, contributing to the organization's mission, etc.) or objective performance measures (Luthans, Avolio, et al., 2007; Luthans et al., 2008; Peterson et al., 2011). Given that PsyCap is primarily cognitive in nature (Luthans, Avolio, et al., 2007; Luthans \& Youssef-Morgan, 2017), measures capturing cognitive aspects of performance can be more relevant to PsyCap. Another tentative explanation for this finding may be that we put all the predictors and the performance outcomes together in the same analysis to enhance statistical rigor. As can be followed from Table 1, task and innovative performance are relatively correlated. Given the conservative statistical tests employed to control for nestedness on performance ratings and to control for the relatively high correlation between these two performance outcomes, the coefficients might be attenuated on the behalf of task performance. Apparently, PsyCap, as a cognitive mechanism, is a better predictor of creative and innovative performance as compared with task performance for which cognitive resources may not be required all the time. In accordance with this argument, the significant effect of PsyCap on innovative performance, but not on task performance, may also speak to recent calls to examine boundary conditions on the relationship between PsyCap and work outcomes (Newman et al., 2014). For example, Schmidt and DeShon (2010) suggested that the relationship between PsyCap and task performance is moderated by performance ambiguity. When there are high degrees of performance ambiguity, PsyCap is unlikely to have a positive influence on job performance and may even have a negative effect since employees do not know how well they are doing. Accordingly, when one's true level of performance is unclear, it must be inferred if one wants to evaluate the 
progress being made toward attaining one's goals. Our sample in the present study consisted of highly educated $(88 \%$ of them had university and higher degrees) white-collar professionals. It might be the case that they are highly expected to engage in creative and innovative work, which might be an important dimension of their performance evaluations, possibly resulting in more emphasis on generation and implementation of new ideas as compared with accomplishment of more general and routine daily tasks. In line with this clear focus on innovative performance, our highly qualified group in the current study might be allocating their efforts and psychological resources more toward innovative tasks to achieve challenging goals.

This significant association between PsyCap and innovative performance in the present study overall implies that PsyCap provides individuals with cognitive and motivational resources to withstand the difficulties of achieving innovative outcomes. Psychologically strong individuals develop a more positive attitude toward their future course of action because they have a better understanding of how to overcome potential problems and produce expected outcomes. They are also more positive in the face of uncertainty, eager to explore opportunities, and persist in their jobs (Luthans, Avolio, et al., 2007; Luthans, Youssef, et al., 2007; Parker, Williams, \& Turner, 2006). Such persistent individuals tend to generate and use alternative approaches for solving problems and demonstrate continuous passion for coming up with new ideas (Zhou \& Shalley, 2008). For instance, resilience might enable followers to reduce the "attempted-yet-failed" fear and thus make them pursue new knowledge and experiences, which constitutes great potential for novel ideas (Amabile, 1988; Huang \& Luthans, 2015). Followers with strong psychological resources also tend to take a broader view and more proactive role in their jobs (Parker et al., 2006). Because of such a thorough understanding of the context in which they work, they are more likely to develop novel and applicable ideas (Oldham \& Cummings, 1996).

Regarding the mediating effects of PsyCap on the relationships between PL and performance, our results showed that PsyCap acts as a mediator between all three dimensions of PL and innovative performance. First, as expected, we identified that PsyCap operates as a mediating mechanism between benevolent leadership and follower innovative performance. Our finding that followers' perceptions of benevolent leadership are positively related to their PsyCap is an original one, which implies that benevolent leaders strengthen their followers' psychological resources and help them cope with problems and obstacles by building and maintaining support both in their personal and professional lives. This emotional and social support from the leader enhances the follower's belief in his or her ability to mobilize the motivation and cognitive resources needed to successfully perform tasks (Luthans, Avolio, et al., 2007;
Luthans \& Youssef-Morgan, 2017). Under such parent-like leaders, followers, especially in difficult times, have a more positive outlook and higher levels of ability to overcome and bounce back from negative work and life events to quickly get over, and recover from stress. Consequently, those psychologically strong followers channel this motivation and energy to look for alternative and creative ways to achieve their goals, take more risks, and exhibit higher levels of innovative performance, as was also implied by previous research (Rego et al., 2012). Identification of PsyCap as a mediating mechanism between benevolent leadership and innovative performance contributes to PL literature, which lacks studies examining this black box. Only recently, Gumusluoglu et al. (2017) reported identification with the team and the department as mechanisms through which benevolent leaders facilitate innovation both within and across teams, respectively. Hence, our study contributes to this line of research by showing that benevolent leaders can foster innovative behavior of the followers at the individual level by strengthening their psychological resources.

Moreover, post hoc analyses illustrate that benevolent leaders have a direct influence on the innovative performance of their followers, as well, and it is the only dimension of PL that had direct effects. Indeed, this finding is consistent with previous research that indicated that in collectivistic contexts, even in R\&D settings where more innovative performance is expected, benevolent leadership is an effective leadership style (Chan et al., 2013; Chan \& Mak, 2012; Chen et al, 2014; Farh \& Cheng, 2000; Gumusluoglu et al., 2017; Karakitapoğlu-Aygün \& Gumusluoglu, 2013a, 2013b). When benevolent leaders show individualized concern for the professional and personal well-being of their subordinates, they feel more valued, which increases their feelings of gratitude to the leader (Wang \& Cheng, 2010). With a strong sense of gratitude toward the leader, subordinates are likely to exert more time and effort on their tasks and go above and beyond their job roles in order to benefit broader organizational goals (Konovsky \& Pugh, 1994). Positive reciprocity beliefs provide an explanation for these follower behaviors since this view suggests that subordinates are likely to reciprocate beneficial behaviors based on their sense of gratitude, indebtedness, and obligation to repay (Umphress, Bingham, \& Mitchell, 2010). When a leader provides long-term care, protection, and nurturance, followers tend to form an emotional bond and a reciprocal relationship with their leaders in order to continue this positive cycle. Farh and Cheng (2000) suggest that employees of benevolent leaders reciprocate by taking assignments seriously, meeting leader's expectations, and working diligently. In such a strong bond-, affect-, and gratitude-based environment, employees also show higher levels of innovative performance since they are more willing to ask questions, seek help, and take risks knowing that mistakes will be tolerated (Edmondson, 1999). 
Second, consistent with our expectations, we found that authoritarian leadership is negatively associated with PsyCap, which mediates the effect on innovative performance. This finding is consistent with previous research, which found that authoritarian leadership is undesirable and even destructive for the psychological well-being of the followers (Chan et al., 2013; Karakitapoğlu-Aygün \& Gumusluoglu, 2013b). Indeed, Pellegrini and Scandura (2008, p. 570) claim that ". . . once exploitation replaces benevolence, and control replaces concern, the relationship moves away from paternalism toward authoritarianism." Followers of such authoritarian leaders are more likely to feel distrust, fear, anger, anxiety, and uncertainty (Guoa et al., 2018; Wu et al., 2011). One common underlying theme of this leadership style is that these leaders have a high need for control, power, and emotional instability, and achieve obedience and submission by commanding, ridiculing, or humiliating, which result in perceptions of hostility among their followers (Ertureten et al., 2013). KarakitapoğluAygün and Gumusluoglu (2013b) indicate that this authoritarian leadership style represents the dark side of PL in Turkey. This qualitative study among R\&D workers illustrated that authoritarian leaders in the Turkish context are perceived to be coercive, and use threats and punishment for goal accomplishment as indicated by the following subordinate quotes: "These leaders are very aggressive. They give orders and threaten people. People work hard not because they respect their leaders, but because they are scared. As such, when employees find an alternative, they quickly leave." Additional comments included, "These leaders create an unhealthy climate. Employees become very unhappy and start judging fairness at the workplace. So many people had severe health problems due to such a negative atmosphere." These comments suggest that such leaders impair their followers' psychological strength, which, in turn, result in poor innovative performance, especially among white-collar professionals as is the case in the current study.

In contrast to benevolent leadership, authoritarian leadership had no direct effect on innovative performance, implying a full mediation via PsyCap. This finding is consistent with reports from the parenting literature, which suggest that restrictive, authoritarian, and obedience-oriented psychological control has adverse effects on adolescents' developmental outcomes such as psychological symptoms, psychological adjustment, self-esteem, and so on (Steinberg, Lamborn, Darling, Mounts, \& Dornbusch, 1994) as compared with behavioral control, which has direct effects more on behavioral outcomes. In other words, overemphasis on obedience to authority impairs adolescents' perceptions of competence and self-reliance rather than creating behavioral problems. This may also be the case in leader-follower relationship where such authoritarian leaders damage subordinates' positive cognitive and motivational beliefs and may even destroy their self-confidence in their ability to accomplish their tasks (Zhang, Tsui, \& Wang, 2011). Put differently, authoritarian leaders attenuate desired behavioral outcomes such as innovative performance at the workplace through exerting psychological control over their followers and impairing their psychological resources.

Third, as expected, we found that authoritative leadership is positively associated with PsyCap, which mediates the effect on innovative performance. Authoritative leaders, who have a high concern about the welfare of their employees and organizations, focus on the development of their employees and help them reach organizational goals by setting expectations about their performance and by providing feedback. When these leaders emphasize goal accomplishment and reduce role ambiguity, followers are motivated to allocate their psychological resources in order to take initiative and reach those goals. Indeed, Newman et al. (2004) indicated that PsyCap is likely to be more effective when employees are provided with greater clarity as to what is expected of them in their job. High levels of goal clarity have also been shown to increase the number of new ideas generated by the employees (Stetler \& Magnusson, 2015). By providing directions and pathways to pursue, authoritative leaders encourage followers to work hard to attain their goals, look for different pathways to achieve goals, and overcome obstacles. Especially when the environment and organizational context do not provide for clear causal linkages between effort and goal attainment, authoritative leaders clarify these perceptions and create such linkages. Thus, these behaviors enhance followers' feelings of hope and optimism, in turn, feelings of pleasure, and intrinsic motivation and enable them to show perseverance toward goals and, when necessary, redirect paths to goals in order to succeed. Furthermore, authoritative leaders provide a procedurally just environment by providing explanations about the rules and procedures and clarifying the expectations from subordinates (Kim \& Mauborgne, 1997). When these leaders create a fair process in the company, employees trust their leaders' intentions. Such a psychologically safe environment brings about positive job-related cognitions on the part of the followers as well as enhanced motivation and initiative taking.

Moreover, we found that authoritative leadership influences innovative performance only via PsyCap, but not directly. One tentative explanation for the nonsignificant direct effect is that there is a strong leader-follower relationship, which allows for a level of leader worship in Turkey. One aspect of this leader worship ritual is that the emotional attachment of the followers is often polarized across the spectrum of love and hate (Ozbilgin, 2011). Accordingly, it can be argued that while benevolent leaders are loved, authoritarian leaders are hated, and authoritative leaders fall in the middle of the spectrum. In other words, 
while authoritative leader behaviors can influence followers' PsyCap, these leaders may not exhibit a "strong enough" leadership style to directly spark high innovative performance among their followers. It is likely that these leaders are not strong role models for their followers unlike benevolent leaders who act like parents and lead by example. This may explain why we did not find a direct effect of authoritative leadership on followers' innovative performance, as compared with benevolent leadership. Clearly, more research is needed on authoritative leadership, now that a reliable and content valid measure is available for research.

\section{Limitations}

This study was conducted in the Turkish context where PL has been consistently found to be effective. Therefore, to examine the generalizability of these findings, future research should investigate the effects of the three dimensions of PL in other cultural contexts where PL is a predominant leadership style (e.g., Asian cultures). In the light of recent studies that indicate that PL can be a successful leadership style even in individualistic environments (Pellegrini, Scandura, \& Jayaraman, 2010), future research comparing different individualistic versus collectivistic or high versus low power distance cultures is needed. In addition, future researchers may also investigate the additive or interactive effects of other leadership styles such as transformational or authentic leadership (Luthans \& Avolio, 2003) together with PL in predicting different work-related outcomes. Such research would reveal the unique effects of dimensions of PL, after controlling for the effects of other leadership styles. We acknowledge that the cross-sectional design in the present study does not allow examination or inferences of causality. Future longitudinal studies would be valuable to examine the causal relationships between dimensions of PL, PsyCap, and performance. The measure of task performance may be another limitation of the study since it included very general items about whether the follower completes the duties and fulfills the responsibilities required, without paying any attention to their quality and complexity. Future studies interested in PsyCap-performance link might employ instruments capturing whether work roles require challenging or high-quality task activities while measuring task performance. Finally, the effect sizes and the amounts of explained variation were relatively small in the current study. For example, as mentioned by Luthans (2012), PsyCap accounts for only about $25 \%$ of the variance in attitudes and behaviors and $10 \%$ of performance. The remaining unexplained variation is made up of numerous other important variables. Therefore, future research could identify other possible mediators (e.g., individuallevel trust, team-level collective efficacy, or empowerment) or moderators (e.g., climate, organizational identification) at different levels to explore individual, team, and organizational outcomes.

Despite these limitations, the mediating role of PsyCap in PL and innovative performance linkage in the present study suggests some practical implications for human resource development and management. Our results imply that the emotional and motivational effects of PsyCap may help individuals get through difficult situations and respond more positively to today's complex job requirements. Accordingly, PsyCap developmental programs may be used to facilitate employee innovation. Moreover, leader development programs should target relational and goaloriented leadership styles, which enhance psychological resources of followers. Leader-subordinate mentoring programs that help strengthen followers' positive psychological resources may also be beneficial especially when followers feel dissatisfied, when they have difficult assignments, or when they encounter uncertainty and risk at the workplace.

Our findings basically imply that leaders can enhance innovative performance at the workplace by exhibiting a benevolent style of leadership, while avoiding authoritarian style. They should build individualized relationships with their followers and show that they care about their followers' work-life balance. Leaders' concern for followers' personal and professional well-being may be especially critical in times of adversity and uncertainty. Therefore, management training and development programs should include both bright and dark sides of PL. Such programs may help leaders how to show personal concern, care, and support in both work and nonwork domains, while avoiding oppressive, punitive, and restrictive behaviors. Finally, authoritative leadership can be suggested as a middle ground for authoritarian leaders who need to shift their leadership style away from being punishing. As authoritative leaders, they can provide goal clarity and direction without being abusive.

\section{Conclusion}

To respond to the rapid changes in the environment, organizations need to invest not only in financial or social capital but also in employees' PsyCap. The current study extends PL and PsyCap literatures by introducing PsyCap as an important mechanism, which sheds light into the effectiveness of this leadership style. We hope that the findings of the study encourage future research on PL and innovative performance, and provide some insight into the leadership skills necessary to create high performance organizations.

\section{Declaration of Conflicting Interests}

The author(s) declared no potential conflicts of interest with respect to the research, authorship, and/or publication of this article. 


\section{Funding}

The author(s) disclosed receipt of the following financial support for the research, authorship, and/or publication of this article: This work was supported by The Scientific and Technological Research Council of Turkey (TUBITAK; Grant No. 114K855).

\section{Note}

1. We reran all the analyses by including these items in the PsyCap scale. Our results remained the same, and their significance levels did not change at all.

\section{References}

Amabile, T. M. (1988). A model of creativity and innovation in organizations. In B. M. Staw \& L. Cummings (Eds.), Research in organizational behavior (pp.123-167). Greenwich, CT: JAI Press.

Amabile, T. M. (1998). How to kill creativity. Harvard Business Review, September-October, 77-87.

Avey, J. B., Luthans, F., \& Youssef, C. M. (2010). The additive value of positive psychological capital in predicting work attitudes and behaviors. Journal of Management, 36, 430-452.

Aycan, Z. (2001). Human resource management in Turkey: Current issues and future challenges. International Journal of Manpower, 22, 252-260.

Aycan, Z. (2006). Paternalism: Towards conceptual refinement and operationalization. In U. Kim, K. Yang, \& K. K. Kwang (Eds.), Indigenous and cultural psychology: Understanding people in context (pp. 445-466). New York, NY: Springer.

Aycan, Z., Kanungo, R. N., Mendonce, M., Kaicheng, Y., \& Deller, J. (2000). Impact of culture on human resource practices: A 10-country comparison. Applied Psychology: An International Review, 49, 192-221.

Aycan, Z., Schyns, B., Sun, J. M., Felfe, J., \& Saher, N. (2013). Convergence and divergence of paternalistic leadership: A cross-cultural investigation of prototypes. Journal of International Business Studies, 44, 962-969.

Bandura, A. (1997). Self-efficacy: The exercise of control. New York, NY: W. H. Freeman.

Berkman, Ü., \& Özen, Ş. (2007). Turkish business system and managerial culture: State dependency and paternalism in transition. In D. E. Dupuis \& J. F. Chanlat (Eds.), Culture and management in the contemporary world [CD-ROM]. Quebec City, Quebec, Canada: Laval University.

Bliese, P. D. (2000). Within-group agreement, non-independence, and reliability: Implications for data aggregation and analysis. In K. J. Klein \& S. W. J. Kozlowski (Eds.), Multilevel theory, research, and methods in organizations (pp. 349-381). San Francisco, CA: Jossey-Bass.

Brislin, R. W. (1970). Back-translation for cross-cultural research. Journal of Cross-Cultural Psychology, 1, 185-216.

Bysted, R., \& Hansen, J. R. (2013). Comparing public and private sector employees' innovative behavior: Understanding the role of job and organizational characteristics, job types, and subsectors. Public Management Review, 17, 1-20.

Chan, S. C. H., Huang, X., Snape, E., \& Lam, C. K. (2013). The Janus face of paternalistic leaders: Authoritarianism, benevolence, subordinates' organization-based self-esteem, and performance. Journal of Organizational Behavior, 34, 108-128.
Chan, S. C. H., \& Mak, W. M. (2012). Benevolent leadership and follower performance: The mediating role of leader-member exchange (LMX). Asia Pacific Journal of Management, 29, 285-301.

Chen, X. P., Eberly, M. B., Chiang, T. J., Farh, J. L., \& Cheng, B. S. (2014). Affective trust in Chinese leaders: Linking paternalistic leadership to employee performance. Journal of Management, 40, 796-819.

Cheng, B., Chou, L., Wu, T., Huang, M., \& Farh, J. (2004). Paternalistic leadership and subordinate responses: Establishing a leadership model in Chinese organizations. Asian Journal of Social Psychology, 7, 89-117.

Chou, W. J., Sibley, C. G., Liu, J. H., Lin, T. T., \& Cheng, B. S. (2015). Paternalistic leadership profiles: A person-centered approach. Group \& Organization Management, 40, 685-710.

Clapp-Smith, R., Vogelgesang, G. R., \& Avey, J. B. (2009). Authentic leadership and positive psychological capital. Organizational Studies, 15, 227-240.

Edmondson, A. (1999). Psychological safety and learning behavior in work teams. Administrative Science Quarterly, 44, 350-383.

Erben, G. S., \& Güneşer, A. B. (2008). The relationship between paternalistic leadership and organizational commitment: Investigating the role of climate regarding ethics. Journal of Business Ethics, 82, 955-968.

Ertureten, A., Cemalc1lar, Z., \& Aycan, Z. (2013). The relationship of downward mobbing with leadership style and organizational attitudes. Journal of Business Ethics, 116, 205-216.

Farh, J. L., \& Cheng, B. S. (2000). A cultural analysis of paternalistic leadership in Chinese organizations. In J. T. Li, A. S. Tsui, \& E. Weldon (Eds.), Management and organizations in the Chinese context (pp. 84-127). London, England: MacMillan.

Farh, J. L., Cheng, B. S., Chou, L. F., \& Chu, X. P. (2006). Authority and benevolence: Employees' responses to paternalistic leadership in China. In A. S. Tsui, Y. Bian, \& L. Cheng (Eds.), China's domestic private firms: Multidisciplinary perspectives on management and performance (pp. 230-260). Armonk, NY: M.E. Sharpe.

Gong, Y., Huang, J. C., \& Farh, J. L. (2009). Employee learning orientation, transformational leadership, and employee creativity: The mediating role of employee creative self-efficacy. Academy of Management Journal, 52, 765-778.

Gooty, J., Gavin, M., Johnson, P. D., Frazier, M. L., \& Snow, D. B. (2009). In the eyes of beholder: Transformational leadership, positive psychological capital and performance. Journal of Leadership \& Organizational Studies, 15, 353-367.

Gumusluoglu, L., \& Ilsev, A. (2009). Transformational leadership, creativity and organizational innovation. Journal of Business Research, 62, 461-473.

Gumusluoglu, L., Karakitapoğlu-Aygün, Z., \& Scandura, T. A. (2017). A multi-level examination of benevolent leadership and innovative behavior in R\&D contexts: A social identity approach. Journal of Leadership \& Organizational Studies, 24, 479-493.

Guoa, L., Decoster, S., Babalola, M. T., De Schutter, L., Garba, O. A., \& Riisla, K. (2018). Authoritarian leadership and employee creativity: The moderating role of psychological capital and the mediating role of fear and defensive silence. Journal of Business Research, 92, 219-230. 
Gupta, V., \& Singh, S. (2015). Leadership and creative performance behaviors in R\&D laboratories: Examining the mediating role of justice perceptions. Journal of Leadership \& Organizational Studies, 22, 21-36.

House, R. J. (1996). Path-goal theory of leadership: Lessons, legacy, and a reformulated theory. Leadership Quarterly, 7, 323-352.

Huang, L., \& Luthans, F. (2015). Toward better understanding of the learning goal orientation-creativity relationship: The role of positive psychological capital. Applied Psychology: An International Review, 64, 444-472.

Janssen, O. (2000). Job demands, perceptions of effort-reward fairness and innovative work behavior. Journal of Occupational and Organizational Psychology, 73(3), 287-302.

Jöreskog, K. G., \& Sörbom, D. (1993). LISREL 8: Structural equation modeling with the SIMPLIS command language. Chicago, IL: Scientific Software International.

Kahn, R. L., Wolfe, D. M., Quinn, R. P., Snoek, J. D., \& Rosenthal, R. A. (1964). Organizational stress: Studies in role conflict and ambiguity. Oxford, England: Wiley.

Karakitapoğlu-Aygün, Z., \& Gumusluoglu, L. (2013a). A re-conceptualization of transformational leadership in the Turkish context. Turkish Journal of Psychology, 28, 105-124.

Karakitapoğlu-Aygün, Z., \& Gumusluoglu, L. (2013b). The bright and dark sides of leadership: Transformational vs. non-transformational leadership in a non-Western context. Leadership, 9, 107-133.

Kim, W. C., \& Mauborgne, R. (1997). Fair process: Managing in the knowledge economy. Harvard Business Review, JulyAugust, 65-75.

Konovsky, M. A., \& Pugh, S. D. (1994). Citizenship behavior and social exchange. Academy of Management Journal, 37, 656-669.

Luthans, F. (2012). Psychological capital: Implications for HRD, retrospective analysis and future directions. Human Resource Development Quarterly, 23, 1-8.

Luthans, F., \& Avolio, B. J. (2003). Authentic leadership development. In K. S. Cameron, J. E. Dutton, \& R. E. Quinn (Eds.), Positive organizational scholarship: Foundations of a new discipline (pp. 241-258). San Francisco, CA: Berrett-Koehler.

Luthans, F., Avolio, B. J., Avey, J. B., \& Norman, S. M. (2007). Positive psychological capital: Measurement and relationship with performance and satisfaction. Personnel Psychology, 60, 541-572.

Luthans, F., Norman, S. M., Avolio, B. J., \& Avey, J. B. (2008). The mediating role of psychological capital in the supportive organizational climate-employee performance relationship. Journal of Organizational Behavior, 29, 219-238.

Luthans, F., \& Youssef, C. M. (2007). Emerging positive organizational behavior. Journal of Management, 33, 321-349.

Luthans, F., Youssef, C. M., \& Avolio, B. J. (2007). Psychological capital: Developing the human competitive edge. New York, NY: Oxford University Press.

Luthans, F., Youssef, C. M., \& Rawski, S. L. (2011). A tale of two paradigms: The impact of psychological capital and reinforcing feedback on problem solving and innovation. Journal of Organizational Behavior Management, 31, 333-350.

Luthans, F., \& Youssef-Morgan, C. M. (2017). Psychological capital: An evidence-based positive approach. Annual Review of Organizational Psychology and Organizational Behavior, 4, 339-366.
Luthans, F., Youssef-Morgan, C. M., \& Avolio, B. J. (2015). Psychological capital and beyond. New York, NY: Oxford University Press.

Mumford, M. D, Scott, G. M., Gaddis, B., \& Strange, J. M. (2002). Leading creative people: Orchestrating expertise and relationships. Leadership Quarterly, 13, 705-750.

Muthén, L. K., \& Muthén, B. O. (1998-2017). Mplus user's guide: Statistical analysis with latent variables (8th ed.). Los Angeles, CA: Muthén \& Muthén.

Newman, A., Ucbasaran, D., Zhu, F., \& Hirst, G. (2014). Psychological capital: A review and synthesis. Journal of Organizational Behavior, 35, 120-138.

Oldham, G. R., \& Cummings, A. (1996). Employee creativity: Personal and contextual factors at work. Academy of Management Journal, 39, 607-634.

Ozbilgin, M. (2011). Leadership in Turkey: Towards an evidence based and contextual approach. In B. Metcalfe \& F. Mimouni (Eds.), Leadership development in the Middle East (pp. 275294). Cheltenham, England: Edward Elgar.

Parker, S. K., Williams, H. M., \& Turner, N. (2006). Modeling the antecedents of proactive behavior at work. Journal of Applied Psychology, 91, 636-652.

Paşa, S. F., Kabasakal, H., \& Bodur, M. (2001). Society, organizations and leadership in Turkey. Applied Psychology: An International Review, 50, 559-589.

Paulsen, N., Maldonado, D., Callan, V. J., \& Ayoko, O. (2009). Charismatic leadership, change and innovation in an R\&D organization. Journal of Organizational Change Management, 22, 511-523.

Pellegrini, E. K., \& Scandura, T. A. (2008). Paternalistic leadership: A review and agenda for future research. Journal of Management, 4, 566-593.

Pellegrini, E. K., Scandura, T. A., \& Jayaraman, V. (2010). Cross-cultural generalizability of paternalistic leadership: An expansion of Leader-Member Exchange theory. Group and Organization Management, 35, 391-420.

Peterson, S. J., Luthans, F., Avolio, B. J., Walumbwa, F. O., \& Zhang, Z. (2011). Psychological capital and employee performance: A latent growth modeling approach. Personnel Psychology, 64, 427-450.

Podsakoff, P. M., \& Mackenzie, S. B. (1989). A second generation measure of organizational citizenship behavior. Unpublished manuscript, Indiana University, Bloomington.

Rego, A., Sousa, F., Marques, C., \& Cunha, M. P. (2012). Authentic leadership promoting employee's psychological capital and creativity. Journal of Business Research, 65, 429-437.

Scandura, T. A. (2017). Paternalistic leadership. Unpublished manuscript, University of Miami, Miami, FL.

Schmidt, A. M., \& DeShon, R. P. (2010). The moderating effects of performance ambiguity on the relationship between self-efficacy and performance. Journal of Applied Psychology, 95, 572-581.

Scott, S. G., \& Bruce, R. A. (1994). Determinants of innovative behavior: A path model of individual innovation in the workplace. Academy of Management Journal, 37, 580-607.

Snyder, C. R., \& Lopez, S. (2002). Handbook of positive psychology. Oxford, England: Oxford University Press.

Steinberg, L., Lamborn, S. D., Darling, N., Mounts, N. S., \& Dornbusch, S. M. (1994). Over-time changes in adjustment and competence among adolescents from authoritative, 
authoritarian, indulgent and neglectful families. Child Development, 65, 754-770.

Stetler, K. L., \& Magnusson, M. (2015). Exploring the tension between clarity and ambiguity in goal setting for innovation: Clarity and ambiguity in goal setting for innovation. Creativity and Innovation Management, 24, 231-246.

Tierney, P., Farmer, S. M., \& Graen, G. B. (1999). An examination of leadership and employee creativity: The relevance of traits and relationships. Personnel Psychology, 52, 591-620.

Umphress, E. E., Bingham, J. B., \& Mitchell, M. S. (2010). Unethical behavior in the name of the company: The moderating effect of organizational identification and positive reciprocity beliefs on unethical pro-organizational behavior. Journal of Applied Psychology, 95, 769-780.

Wang, A. C., \& Cheng, B. S. (2010). When does benevolent leadership lead to creativity? The moderating role of creative role identity and job autonomy. Journal of Organizational Behavior, 31, 106-121.

Wang, M., \& Takeuchi, R. (2007). The role of goal orientation during expatriation: A cross-sectional and longitudinal investigation. Journal of Applied Psychology, 92, 1437-1445.

Wasti, S. A., Tan, H. H., \& Erdil, S. E. (2010). Antecedents of trust across foci: A comparative study of Turkey and China. Management and Organization Review, 7, 279-302.

Webber, S. S. (2002). Leadership and trust facilitating cross-functional team success. Journal of Management Development, 21, 201-214.

West, M. A., \& Farr, J. L. (1989). Innovation at work: Psychological perspectives. Social Behavior, 4, 15-30.

Woolley, L., Caza, A., \& Levy, L. (2010). Authentic leadership and follower development: Psychological capital, positive work climate and gender. Journal of Leadership \& Organization Studies, 20, 1-11.

Wu, M., Huang, X., Li, C., \& Liu, W. (2011). Perceived interactional justice and trust-in-supervisor as mediators for paternalistic leadership. Management and Organization Review, 8, 97-121.

Zhang, A. Y., Tsui, A. S., \& Wang, D. X. (2011). Leadership behaviors and group creativity in Chinese organizations: The role of group processes. Leadership Quarterly, 22, 851-862.
Zhang, Y., Huai, M. Y., \& Xie, Y. (2014). Paternalistic leadership and employee voice in China: A dual process model. Leadership Quarterly, 26, 25-36.

Zhou, J., \& Shalley, C. E. (2008). Expanding the scope and impact of organizational creativity research. In J. Zhou \& C. E. Shalley (Eds.), Handbook of organizational creativity (pp. 125-147). New York, NY: Lawrence Erlbaum.

\section{Author Biographies}

Zahide Karakitapoğlu-Aygün is an associate professor at Faculty of Business Administration at Bilkent University. Her research interests include commitment, leadership, organizational justice, team innovation and perceived overqualification. She published in several journals such as Journal of CrossCultural Psychology, Personality and Social Psychology Bulletin, Journal of Product and Innovation Management, Leadership, Journal of Business Ethics, European Journal of Social Psychology, Journal of Social Psychology, Journal of Leadership and Organizational Studies, and Journal of Business Research.

Lale Gumusluoglu is an assistant professor at Faculty of Business Administration at Bilkent University. Her research interests include leadership, knowledge workers, individual and team-level innovation \& creativity, commitment, ethics and justice. Her papers were published in journals such as Journal of Product Innovation Management, Journal of Business Research, Journal of Leadership and Organizational Studies, Leadership and European Management Review.

Terri A. Scandura is the Warren C. Johnson endowed professor of Management in the Miami Business School at the University of Miami. Her research interests center on leadership, mentorship, and teams. Her papers appeared in journals such as Academy of Management Journal, Journal of Applied Psychology, Leadership Quarterly, Journal of International Business Studies, Journal of Vocational Behavior, and Journal of Organizational Behavior. 